\title{
Fatores clinicos e psicológicos na dor facial e temporomandibular severa usando análise bivariada e de regressão múltipla
}

\section{Clinical and psychological factors in severe facial and temporomandibular joint pain using bivariate and multiple regression analysis.}

\author{
Omar Franklin Molina ${ }^{1}$ \\ Rise Consolação Iuata Costa Rank ${ }^{2}$ \\ Zeila Coelho Santos ${ }^{3}$ \\ Márllos Peres de Melo ${ }^{4}$ \\ Rogério Ferreira Marchezan ${ }^{5}$ \\ Marcelo Bressan Corrêa ${ }^{6}$
}

\section{Palavras-chave:}

Distúrbios

Temporomandibulares

Dor

Ansiedade

Depressão

\section{Resumo:}

Objetivos: Avaliar o papel de fatores psicológicos específicos em uma amostra de 80 indivíduos com DCMs e dor facial e ou temporomandibular severa e 30 controles com dor mas sem DCMs. Materiais e Métodos: 80 indivíduos com dor facial e ou temporomandibular severa foram avaliados de forma retrospectiva. Exame clinico, história da queixa principal, critérios para DCMs, distúrbios internos articulares, bruxismo leve, moderado, severo e extremo foram usados. Análise bivariada e regressão múltipla foram usadas para obter dados. Resultados: A dor foi mais severa no grupo DCM do que no controle $(\mathrm{p}<0.0001)$. Houve diferenças estatisticamente significantes no grupo DCM e no controle em relação com locais com dor, duração, freqüência e severidade da dor, severidade do bruxismo, e valores em ansiedade, depressão e somatização. A análise bivariada demonstrou que locais com dor-severidade, bruxismo-severidade da dor, ansiedade-severidade da dor, depressão-severidade da dor e somatização-severidade da dor estavam correlacionadas positivamente. $\mathrm{O}$ modelo de regressão múltipla demonstrou que todos os fatores psicológicos podiam contribuir com $16.36 \%$ da variância, entretanto, a ansiedade, depressão, somatização fizeram a contribuição mais significante (13.11\%) sobre a severidade da dor. Conclusões: A dor severa em indivíduos com DCM estava relacionada com ansiedade, depressão e somatização e sua contribuição foi positiva e significante.

\section{Abstract}

Aims: Evaluate the role of the specific psychological factors in 80 individuals with CMDs and facial and/or temporomandibular pain and 30 with pain but without CMDs. Material and Methods: $80 \mathrm{CMD}$ individuals with facial and/or temporomandibular severe pain were evaluated in a retrospective way. Clinical examination, history of the main complaint, criteria for CMD, internal joint disorders and bruxism behavior were used. Bivariate analysis and a multiple regression model were used to obtain data. Results: Pain was more severe in the CMD group than in the controlled one $(\mathrm{p}<0.0001)$. There were signifi-
Key words:

Temporomandibular

Disorders

Pain

Anxiety

Depression

1 MDS, PA, Post Doct in Orofacial Pain, Ex research associate (1997-2003) University of Texas, Ex Fellow Harvard University, USA, Research Associate UNIRG-TO.

2 DDS, MDS, Graduate student (Ph.D) SLM University, Campinas, SP.

3DDS, MDS in Orthodontics, Professor of Orofacial Pain UNIRG-TO.

4MDS, Consultant and Professor of Statistics, UNIRG-TO

5MDS, Professor of Psychology, Vice-Dean for student affairs UNIRG-TO,Brazil.

6 MDS, Professor of Prosthetic Dentistry and Implants, ITPAC, Araguaína-TO. 
cant differences in CMD and in controlled individuals regarding place, duration, frequency and severity of pain, bruxism severity and anxiety, depression and somatization scores. Bivariate analysis demonstrated that areas with pain severity, bruxism severity, anxiety severity, depression severity and somatization severity were positively correlated. The multiple regression model showed that all the psychological factors can contribute with $16.36 \%$ of variance. However, anxiety, depression and somatization made the most significant contribution $(13.11 \%)$ in pain severity. Conclusion: Severe pain in CMDs individuals was closely related to anxiety, depression and somatization and their contribution was positive and significant.

\section{Introduction and literature review}

Pain is currently defined as an unpleasant sensory and emotional experience associated with actual or potential tissue damage, or described in terms of such damage (1). Chronic pain is pain present for longer than six months and pain intensity may be influenced by nociception, environmental and psychological factors (2). There has been growing recognition that pain is a perceptual experience influenced by a wide range of psychological factors including emotions, social and environmental context, socio-cultural background, the meaning of pain to the person, beliefs, attitudes and expectations (3). Patients' perception of pain, the impact of pain on their lives, dysphoric mood and responses of significant others, all contribute to pain of greater intensity and disability (4). Anxiety, depression and the tendency to express pain in multiple sites have been demonstrated to be associated with elevated symptoms in chronic facial and temporomandibular joint pain patients (3). Persistent orofacial pain occurs more frequently in females, older age, in those with psychological distress, widespread pain and excessive medication intake (5). Bruxism, the most common factor found in CMD, refers to a non functional grinding and clenching of the teeth and the continuous pressure can damage the temporomandibular joints (6). Anxiety and other affective disorders particularly depression, somatization and personality disorders, may occur more frequently in CMD patients than in control subgroups (7). Because there are only a few studies on specific subgroups of severe facial and temporomandibular joint pain, the goals of this study are fivefold:
1. Compare scores of some clinical and psychological variables between CMDs and Non-CMD control individuals;

2. Evaluate some results of bivariate analysis which may contribute to the understanding of severe pain.

3. Test the hypothesis that anxiety, depression and somatization are important elements contributing to the maintenance of pain in this subset of severe CMD patients, using a multiple regression analysis;

4. Test another hypothesis that more pain is more depressing, and thus, there is a significant and positive correlation between depression and severity of pain.

5. Assess the hypothesis that bruxism is more severe in this subset of CMD and bruxing behavior individuals.

\section{Materials And Methods}

Data for this research were gathered retrospectively from 250 craniomandibular

Disorders (CMDs) and bruxing behavior cases referred consecutively to a Center for the Study of CMD, Orofacial Pain and Oral Jaw Habits to the University of GurupiTO in the years 2003-2010. Each evaluated chart contained valuable data about signs and symptoms of CMDs, the most common types of headache and bruxing behavior classified as mild, moderate, severe and extreme according to the number of signs and symptoms. Information about tenderness to palpation, types and description of pain (including sever- 
ity using the Visual Analogue Scale, VAS) in the masticatory system, description of miofascial pain, types and characteristics of specific internal derangements of the TMJ, type and characteristics of the headache and/or facial pain including duration, frequency, intensity, was also be recorded in the charts. The charts also contained a short questionnaire to assess the presence of pain adjacent and distant to the masticatory system. Patients were classified as presenting CMDs if they demonstrated specific signs/symptoms including a complaint of pain in the masticatory muscles, noises in the temporomandibular joint, difficulties to perform lateral or opening jaw movements, tenderness in the masticatory muscles during palpation, and headaches usually of muscle origin. Patients were classified as presenting CMDs and bruxing behavior according to criteria published previously $(\mathbf{8 , 9})$.

Results of specific tests, including the TMAS (Taylor Manifest Anxiety Scale) for anxiety, the BDI for depression and the Hiller inventory for somatisation, was also found in every chart. The TMAS presents 28 self reported (yes or no) questions than can be answered easily and quickly by any individual. It is a robust method that assesses anxiety. The BDI (Beck Depression Inventory) is a robust widely known method to assess depression. It has 21 questions evaluating depression and every question is presented hierarchically so the value of every question can range from 0 to 3 . The test presents a maximal score of 63 and a minimum of zero. The Hiller scale for somatisation has 32 yes or no questions assessing many items related to somatisation and bodily dysfunction. Such questionnaire is easy to understand and apply being widely used in medical and psychological research. The information from 80 charts from CMD individuals with bruxing behavior and severe bilateral facial or TMJ pain, was retrieved so as to study correlations of these psychological factors with other clinical variables, for instance, severity, duration, pain in multiple sites and frequency of pain and to include such variables in a multiple regression model. The control group was formed by 40 individuals presenting no bruxing behavior, no CMD but a complaint of pain. Subjects in that group had been referred consecutively for examination and diagnosis in the same period of time. All patients were informed about the characteristics of the study, and signed a written consent to participate.

Inclusion criteria for subjects in this study:

1. A complaint in the field of Craniomandibular Disorders

2. Patients with bilateral facial or temporomandibular joint painPain described as severe

3. Presence of musculoskeletal disorders

4. Seeking active treatment for a CMD complaint.

5. A previous diagnosis of all conditions, stated clearly in the chart

Exclusion criteria:

1. Presence of neuropathic and neurogenic pain

2. Presence of cervicogenic headache, psychogenic pain, atypical facial pain and atypical odontalgia.

3. Presence of dental pain attributed to dental pathology

4. Observation of sign and symptoms of neurological and major psychiatric disorders;

5. Being in treatment for craniomandibular disorders in other institution

Statistical analysis: Tests used in this study included Mann-Whitney Statistics, Pearson Product Moment Correlation, unpaired t test with Welch's correction and multiple regression analysis. Stepwise regression was used in this study. Initially all variables were included in the regression equation and the variables that contributed the less, were observed and deleted from the set of variables (backward elimination). In a second step, we selected a set of variables which did the most significant contribution in the study, thus, a new model was worked out (forward selection) and the contribution of this new set of variables was entered in the InStat program. 


\section{Results}

The results of this investigation are shown in tables I through IV.

\begin{tabular}{|c|c|c|c|c|}
\hline \multirow[t]{3}{*}{ GENRE } & \multicolumn{2}{|c|}{ CMD CASES } & \multicolumn{2}{|c|}{ CONTROLS } \\
\hline & \multicolumn{2}{|c|}{$\mathrm{N}=80$} & \multicolumn{2}{|c|}{$\mathrm{N}=40$} \\
\hline & $\mathrm{N}$ & $\%$ & $\mathrm{~N}$ & $\%$ \\
\hline Males & 6 & 7.5 & 11 & 27.5 \\
\hline Females & 74 & 92.5 & 29 & 72.5 \\
\hline Totals & 80 & 100.0 & 40 & 100.0 \\
\hline Mean age & \multicolumn{2}{|c|}{35.3} & \multicolumn{2}{|c|}{34.1} \\
\hline SD & \multicolumn{2}{|c|}{11.7} & \multicolumn{2}{|c|}{12.07} \\
\hline Range & \multicolumn{2}{|c|}{$16-75$} & \multicolumn{2}{|c|}{$20-62$} \\
\hline
\end{tabular}

Table II. Mean scores in severity of pain, painful sites, pain duration (in years), frequency, bruxism, anxiety, depression and somatisation in patients and controls.

\begin{tabular}{|c|c|c|c|c|c|c|c|c|}
\hline & \multicolumn{3}{|c|}{ CMD cases } & \multicolumn{2}{|c|}{ Controls } & & Test & $\mathrm{p}$ value \\
\hline & $\mathrm{N}=8$ & & & $\mathrm{~N}=$ & 40 & & & \\
\hline Variable & Mean & SD & Range & Mean & SD & Range & & \\
\hline Severity of pain & 9.1 & 0.7 & $8-10$ & 5.9 & 1.7 & $3--9$ & Mann-Whitney & 0.0001 \\
\hline Painful sites & 6.5 & 2.0 & $2-10$ & 3.8 & 2.6 & $0--10$ & Mann-Whitney & 0.0001 \\
\hline Duration & 7.4 & 8.4 & $0.2-40$ & 6.2 & 11.2 & $20.1-59$ & Mann-Whitney & 0.006 \\
\hline Frequency & 20.4 & 10.6 & $3-30$ & 15.6 & 12.0 & $0.5-30$ & Mann-Whitney & 0.02 \\
\hline Bruxism & 11.2 & 2.8 & $5-18$ & 6.0 & 3.9 & $0-14$ & Mann-Whitney & 0.0001 \\
\hline Anxiety & 16.2 & 5.8 & $4--28$ & 17.4 & 7.0 & $6-28$ & Unpaired $\mathrm{t}$ test & 0.04 \\
\hline Depression & 14.8 & 6.4 & $3--30$ & 6.7 & 4.7 & $0--17$ & Mann-Whitney & 0.0001 \\
\hline Somatisation & 13.2 & 4.2 & $3--22$ & 6.9 & 4.8 & $0-18$ & Unpaired $t$ test & 0.0001 \\
\hline
\end{tabular}

Table III. Results of bivariate analysis (Pearson $r$ ) between pairs of variables of interest in the group of CMD individuals with severe facial and TMJ pain $(\mathrm{N}=80)$.

$\begin{array}{lllc}\text { Pairs of variables } & \text { Pearson } \mathrm{r} & \mathrm{p} \text { value } & \text { Significant? } \\ \text { Painful areas--Severity } & 0.25 & 0.02 & \text { Yes } \\ \text { Duration-Severity } & 0.03 & 0.74 & \text { No } \\ \text { Frequency-severity } & -0.00 & 0.79 & \text { No } \\ \text { Bruxism---Severity } & 0.24 & 0.02 & \text { Yes } \\ \text { Anxiety----Severity } & 0.24 & 0.03 & \text { Yes } \\ \text { Depression-Severity } & 0.26 & 0.01 & \text { Yes } \\ \text { Somatisation---severity } & 0.22 & 0.04 & \text { Yes }\end{array}$


Table IV: Analysis of the variance/contribution of each individual independent variable on the dependent variable (Severity of pain).

$\begin{array}{lccc}\text { Independent variable } & \text { Variance or contribution } & \text { p value } & \text { Significant? } \\ \text { Anxiety }^{*} & 2.71 \% & 0.008 & \text { Yes } \\ \text { Depression }^{*} & 2.10 \% & 0.19 & \text { No } \\ \text { Duration }^{*} & 1.58 \% & 0.26 & \text { No } \\ \text { Somatisation }^{*} & 4.54 \% & 0.05 & \text { Yes } \\ \text { Bruxism }^{*} & 0.32 \% & 0.61 & \text { No } \\ \text { Frequency }^{*} & 0.07 \% & 0.82 & \text { No } \\ \text { Pain sites }^{*} & 1.05 \% & 0.36 & \text { No } \\ \text { All independent variables }^{* *} & 16.36 \% & 0.06 & \text { Not quite } \\ \text { Anxiety+Depression+somatization }^{* * *} & 13.11 \% & 0.01 & \text { Yes }\end{array}$

"Variance or contribution (\%) of each independent variable $(\mathrm{X})$ on the dependent variable $(\mathrm{Y})$, $\mathrm{p}$ value and significance.

** Variance or contribution (\%) when all independent variables were entered at once into the model and significance of the total contribution on severity of pain (Y). ${ }^{* * * *}$ A new model was constructed using three independent variables which made the most significant contribution: Contribution to the variance $13.11 \%, \mathrm{p}=0.01$.

Table 1 shows that the mean age in the CMD group was about 35.3 years $(\mathrm{SD}=11,7$, Range $=16-75)$ as compared to 34.1 years $(\mathrm{SD}=12.0$, Range $=20-62)$ in the control group. Table II demonstrates that the mean severity of pain in the CMD group was about 9.1 and 5.9 in the control group (Mann-Whitney test $p=0.0001$, extremely significant difference). The number of painful sites was about 6.5 and 3.8 in the CMD and control group respectively (Mann-Whitney test $\mathrm{p}=0.0001$, extremely significant difference). The mean duration of pain was about 7.4 years in the CMD group and 6.2 years in the control group (Mann-Whitney test $\mathrm{p}=0.006$, very significant ). The mean frequency of pain was about 20.4 episodes in the CMD group and 15.6 episodes (per month) in the control (Mann-Whitney statistics $\mathrm{p}=0.02$, very significant ). Mean score in bruxism was about 11.2 in the CMD group and 6.0 in the control group (Mann-Whitney test $\mathrm{p}=0.0001$, an extremely significant difference). The mean score in anxiety was about 16.2 in the CMD group and 17.4 in the control group (unpaired $t$ test, $p=0.04$, a significant difference). The mean score in depression was about 14.8 in the CMD group and 4.7 in the control (Mann-Whitney test $\mathrm{p}=0.0001$, an extremely significant difference). The mean score in somatization was about 13.2 in the CMD group and 4.8 in the control and the difference was extremely significant (Unpaired $t$ test $\mathrm{p}=0.0001$ ).

Table III demonstrates that using Pearson correlation coefficient in the pair of variables painful areas/severity, duration/ severity, frequency/severity, bruxism/severity, anxiety/severity, depression/severity and somatisation/severity, the correlation coefficients were $0.25(\mathrm{p}=0.02), 0.03(\mathrm{p}=0.74),-0.00$ $(\mathrm{p}=0.79), 0.24 \quad(\mathrm{p}=0.02), 0.24 \quad(\mathrm{p}=0.03), 0.26$ $(\mathrm{p}=0.01)$ and $0.22(\mathrm{p}=0.04)$, respectively. Five of these coefficients were positive and significant. Table IV shows that the contribution of all independent variables to the variance was about $16.36 \%$. The independent variables which contributed the most to the model were somatisation $(4.54 \%)$, anxiety $(2.71 \%)$ and depression $(2.10 \%)$. The total contribution of all independent variables was about $16.36 \%$. When anxiety, depression and somatization when taken separately to form a new model, they contributed with $13.11 \%$ of the variance on the dependent variable (severity of pain). 


\section{Discussion}

\subsection{Clinical and psychological varia- bles in CMD individuals with more chronic and severer pain:}

In the current investigation scores in severity of pain, painful sites, duration of pain, frequency of pain, bruxism, anxiety, depression and somatisation, were higher in CMD patients as compared to controls and the differences were statistically significant. Thus, the results of this study are supported at least in part by one study (10) indicating that there is a long standing association between chronic facial pain and psychological distress particularly depression. The results of our study are also in line with one study (11) indicating that persistent and severe chronic pain is associated with the lowest health related quality of life, fear, anger, tension, worry, frustration, irritability and sadness as the most prevalent negative mood types. Because the clinical and psychological variables that were compared with the control group were the same entered in the regression model, and one study (12) reported that a common set of variables is associated with pain in all of the subjects with CMD, such findings provide additional support for the results of the current investigation. In the current study we identified a CMD group presenting with severe pain, thus, findings in this study are similar to those in one investigation (13) indicating that the dysfunctional group was distinguished from the combined sample of chronic pain patients by higher than average levels of pain severity.

\subsection{Results of bivariate analysis: Painful areas and pain severity:}

In the current investigation we report a positive and significant correlation between pain in multiple sites and pain severity ( $\mathrm{r}=0.25, \mathrm{p}=0.02$ ), Thus the results of the current study are supported by one research (14), defending the notion that among pain sufferers, greater pain intensity is associated with more bodily pain sites. Additionally, one investigation (7), evaluated clinical cases at baseline and two years later and reported that the stronger predictors of orofacial pain were chronic widespread pain and higher levels of health anxiety. Sherman and coworkers (15), did not report the severity of pain, however, they found that the number of masticatory muscle sites perceived as painful to palpation was associated with somatisation and such affect is closely related to pain intensity and depression.

\section{Bruxism and severity of pain}

In the current investigation, we report a mean of $11.2 \mathrm{sign} / \mathrm{symptoms}$ indicating the presence of bruxing behavior. Thus, based on a scale to assess the severity of bruxing behavior presented in a previous study (8), most individuals in this selected group presented with severe bruxism. Consequently, the results of the current research are in part supported by another study (16) indicating that certain myofascial pain dysfunction patients are considered to represent a population that suffer from a stress disorder whereby increased anxiety or tension predisposes to jaw clenching or bruxism with attending masticatory miospasm and pain. Additionally, one study (7), using multivariate analysis reported that grinding and clenching, anxiety, depression, health anxiety, other somatic symptoms and chronic widespread pain, were significantly associated with new onset of chronic orofacial pain. Parafunctional behaviors, specifically, muscle tension and emotional states differ among people diagnosed with CMD and are strongly related to jaw and facial pain levels in CMD and control subjects (12).

\section{Anxiety and pain severity}

In the current investigation, we report a positive correlation between anxiety and pain severity (Pearson $\mathrm{r}=0.24, \mathrm{p}=0.03$ ), indicating that in some fashion, anxiety influences pain severity or vice-versa. Anxiety levels have been shown to predict pain severity and pain behavior in acute and chronic pain patients (17), Furthermore, in large sample of patients with different orofacial pains, anxiety showed a weak to moderate positive relationship to pain severity (18), providing additional support for the results in the current study. Anxiety causes increased muscle tension in the skeletal mus- 
cle and thus, may initiate or perpetuate pain. Multivariate studies in a large sample of the population (7) demonstrated that the strongest predictor of orofacial pain were health anxiety, chronic widespread pain and age.

\section{Depression and pain severity}

In the current investigation we report a positive and statistically significant correlation between depression and pain severity (Pearson $\mathrm{r}=0.26, \mathrm{p}=0.01$ ). Thus the results of the current study are supported by one investigation (7) indicating that psychological factors may potentially increase orofacial pain associated with suffering and regional muscle contraction. In another study (18), depression scores showed a weak though significant positive relationship to pain severity. Depression motivates orofacial pain patients to seek care, report more symptoms and a longer duration of pain (18). Among pain sufferers, depression is associated with greater pain intensity and unpleasantness , more bodily pain sites and a higher degree of pain-related disability (14). Patients with chronic pain are a homogeneous group for whom pain is a somatic expression of repressed emotional conflict (19).

\section{Somatisation and pain severity}

In the current study we report a positive and statistically significant correlation between somatisation and pain severity ( Pearson $\mathrm{r}=0.22, \mathrm{p}=0.04$ ). Thus, the results of this study are supported by one investigation (2), indicating that psychological factors can influence patient's subjective reports of pain intensity and descriptions for reasons such as secondary emotional gain or securing increased narcotic medication. Additional support for the results of the current investigation comes from one experimental study (15), asserting that high somatizers may perceive more pain in response to muscle pressure in an area of the body which is vulnerable to pain. CMD patients may have higher somatisation scores, more muscle pain sites and thus, severer pain (20).
4.3. Anxiety, depression and somatization made a significant contribution to severity of pain in a multiple regression model.

Because somatisation is closely related to depression and pain in multiples sites and both are linked to depression, the results of the current study are supported at least in part by one study (21), showing that patients with a number of pain conditions were at a higher risk for depression. All patients in this study were both CMD and bruxers. Patients with higher scores in somatisation are expected to be at greater risk for pain as they present pain in multiple sites. They are also at greater risk for depression as somatisation and depression are linked one to the other. Supporting this point of view, one study (22) reported that the most frequent bruxers demonstrated pain in multiple sites (somatisation) and depression Such pains could increase both the severity of pain and the likelihood for depression. In one study (23), $24 \%$ of those patients reporting pain at 2 or more sites evidenced severe anxiety or depression. In our study there were many patients reporting pain in multiple sites, a feature which is probably related to higher scores in somatization. In the regression model presented in the current study it can be observed that various factors contributed to the severity of pain. Thus, the results of this study are in accordance with another investigation (13) indicating that patients' perception of pain, the impact of pain in their lives, control of pain in their lives, dysphoric mood, responses of significant others and levels of activity, all contribute to pain and disability. Glaros and associates (12), evaluated the role of parafunctions, emotions, and stress in predicting facial pain in subgroups of individuals presenting with myofascial pain, myofascial pain and arthralgia, disk displacement and control subgroups without CMD in their regression analysis. They reported that one of their models yielded $46.2 \%$ of the variance and that intensity of tooth contact, mood, greater effort, depression and increased stress were associ- 
ated with more pain. Such higher variance value may be related with to the fact that they assessed patients with different intensities of pain and different independent variables. Even though their regression model did not include frequency, duration and anxiety, but included depression, tooth contact (bruxism), severity of pain and depression, all the predictor variables contributed independently to jaw pain. Thus, the results of their study substantiated in part the outcome of the current investigation.

\subsection{Depression and pain severity:}

In the current investigation we report a mean BDI score of 15.9 in this subset of chronic and severe orofacial pain patients. Additionally, because Pearson $\mathrm{r}=0.26$ and $\mathrm{p}=0.01$, indicating a positive relationship between depression and severity, the outcome of this study is supported by one investigation (21), indicating that psychological factors may potentially increase orofacial pain through suffering and accentuated muscle contraction increasing pain intensity. Patients with more intense pain become more anxious and depressed (18). Among pain sufferers, depression is associated with greater pain intensity and unpleasantness, more bodily pain sites and a higher degree of pain-related disability (14). According to Blumer and Heilbronn (19), patients with chronic pain suffer from "pain prone disorders", and are a homogeneous group for whom pain is a somatic expression of repressed emotional conflict, a form of masked depression.

\subsection{Severity of bruxism}

The mean of bruxing behavior in this study was about 11.2 indicating the presence of severe bruxism in this subset of severe pain patients. Consequently, such results have partial support in another investigation (16), suggesting that myofascial pain patients represent a population that suffer from a stress disorder whereby increased anxiety or tension predisposes to jaw clenching or bruxing with attending myospasm and pain. Putative risk factors for orofacial pain measure at baseline include teeth grinding, anxiety, depression, other somatic symptoms and chronic widespread pain (7). Parafunctional behaviors including low level and of longer duration muscle tension can produce CMDs strongly related to jaw and facial pain levels. Intense muscle tension and parafunctional activity may have multiple biological consequences, including micro-trauma to the joint and muscles, increased levels of pro-inflammatory cytokines in the joint and sensitization of pain pathways, thus leading to more intense pain (12).

\section{Implications with treatment}

In this subset of CMD and bruxing behavior patients with severe craniofacial pain, bivariate analysis demonstrated that there was a positive and significant correlation between painful areas, bruxism, depression, somatization and the severity of pain. Because a multiple regression analysis model showed that the psychological factors that made the most significant contribution were anxiety, somatization and depression, such findings indicate that in CMD individual with chronic and severe pain, other modes of treatment including anti-anxiety drugs, antidepressants, muscle relaxants and psychologic/psychiatric treatments should be implemented to the traditional CMD (splints, heat, and analgesics) approach, in such a fashion that match the psychological and clinical characteristics of each individual in order to enhance the clinical results of CMD treatment. 


\section{References}

1. Merskey.; H, Bogduk, N. Classification of chronic pain: Description of chronic pain syndromes and definitions of pain terms. IASP, v.1, p.53-56, 1994.

2. Vickers, E.R.; Cousins, M.J.; Woodhouse, A. Pain description and severity of chronic orofacial pain conditions. Australian Dental Journal, v.43, p.403-409, 1998.

3. 3.Turk, D.C.; Okifuji, A. Psychological factors in chronic pain: Evolution and revolution. Journal Consulting Clinical Psychology, v.70, p.678-690, 2002.

4. Turk D.C. Strategies for classifying chronic orofacial pain conditions. Anesthesia Progress, v.37, p.155-160, 1990.

5. MacFarlane, T.V.; Blinkhorn, A.S.; Davies, R.M.; Kincey, K.; Worthington, H.V.

6. Predictors of outcome for orofacial pain in the general population: a four-year follow-up study. Journal Dental Research, v.83, p.712-717, 2004.

7. Lavigne, G.J.; Khoury, S.; Abe, S.; Yamaguchi, T.; Raphael, K. Bruxism, physiology and pathology; an overview for clinicians. Journal of Oral Rehabilitation, v.35, p.476-494, 2008.

8. Aggarwal, V.R.; MacFarlane, G.J.; Farragher, T.M.; McBeth, J. Risk factors for onset of chronic orofacial pain. Results of the North Cheshire Orofacial pain prospective study. Pain, v, 149, p.354$359,2010$.

9. Molina, O.F.; dos Santos, J.; Nelson, S.J.; Nowlin, T.; Grossman, E. Prevalence of modalities of headache and bruxism among patients with craniomandibular disorders. Cranio, v. 15, p.314-325, 1997.

10. Molina, O.F.; Tavares, G.P.; Aquilino, R.N.; Rank, R.; Coelho, S.Z.; César, E.W.;

11. Dib, J.E. Depression, pain in single and multiple sites. Revista Neurociencias, v.15, p.10-17, 2007.
12. Madland, G.; Feinman, C. Chronic facial pain: a multidisciplinary problem. Journal

13. Neurology, Neurosurgery and Psychiatry, v.71, p.716-719, 2001

14. Stohler, C.S. chronic orofacial pain: Is the puzzle unraveling? Journal of Dental Education, v.65, p.1383-1392, 2001.

15. Glaros, A. G.; Williams, K.; Lausten, L. The role of parafunctions, emotions, and stress in predicting facial pain. JADA, v.136, p.451-458, 2005.

16. Rudy, T.E.; Turk, D.C.; Zaki, H.S.; Curtin, H.D.An empirical taxometric alternative to traditional classification of temporomandibular disorders. Pain, v.36, p.311-320, 1989

17. Dickens, C.; McGowan, L.; Dale, S. Impact of depression on experimental pain perception: A systematic review of the literature with meta-analysis. Psychosomatic

18. Medicine, v.65, p.369-375, 2003.

19. Sherman, J.J.; LeResche, L.; Huggins, K.H.; Mancl, L.A.; Sage, J.A.; Dworkin, S.F. The relationship of somatisation and depression to experimental pain response in women with temporomandibular disorders. Psychosomatic Medicine, v.66, p.852-860, 2004

20. Greene, C.S.; Olson, R.E.; Laskin, D.M. The etiology, progression and treatment of myofascial pain dysfunction. JADA, v.105, p.443-448, 1982.

21. Kain, Z,N.; Severino, F.; Alexander, G.M.; Pincus, S.; Mayer, L.C. preoperative anxiety and postoperative pain in women undergoing hysterectomy-a repeated measures design. Journal of Psychological Research, v.49, p.417-422, 2000.

22. Marbach, J.J.; Lund, P. Depression, anhedonia and anxiety in temporomandibular joint and other facial pain syndromes. Pain, v.11, p.73-84, 1981. 
23. Blummer, D.; Heilbronn, M. Chronic pain as a variant of depressive disease: The pain-prone disorder. Journal of Nerve and mental Disease, v.170, p.381-406, 1982.

24. Turner, J.A.; Dworkin, S.F. Screening for psychosocial risk factors in patients with chronic orofacial pain. JADA, v.135, p.1119-1125, 2004.

25. Dworkin, S.F.; Turner, J.A.; Mancl, L.A. A randomized clinical trial of a tailored comprehensive care treatment program for temporomandibular disorders. Journal of Orofacial Pain, v. 16, p.259-276, 2002.

26. Kampe, T.; Edman, G.; Bader, G.; Tagdae, T.; Karlsson, S. Personality traits in a group of subjects with long standing bruxing behavior. Journal of Oral Rehabilitation, v.24, p.588-593, 1997.

27. Von Korff, M.; Dworkin, S.F.; LeResche, L.; Kruger, A. An epidemiologic comparison of pain complaints. Pain, v.32, p.173-183, 1988.

\section{Endereço para Correspondência:}

Omar Franklin Molina

omarmolinatinoco@yahoo.com

Avenida Pará, 1544

Gurupi - TO

CEP: 77400-020

Informações bibliográficas:

Conforme a NBR 6023:2002 da Associação Brasileira de Normas Técnicas (ABNT), este texto científico publicado em periódico eletrônico deve ser citado da seguinte forma: MOLINA, Omar Franklin; RANK, Rise Consolação Iuata Costa; SANTOS, Zeila Coelho; MELO, Márllos Peres de; MARCHEZAN, Rogério Ferreira; CORRÊA, Marcelo Bressan. Fatores clinicos e psicológicos na dor facial e temporomandibular severa usando análise bivariada e de regressão múltipla. Cadernos UniFOA. Volta Redonda, Ano VII, n. 18, abril 2012. Disponível em: <http://www.unifoa.edu,br/cadernos/edicao/18/75 pdf 